\title{
Incremental burden of comorbid major depressive disorder in patients with type 2 diabetes or cardiovascular disease: a retrospective claims analysis
}

Anne Kangethe ${ }^{1}$, Debra F. Lawrence ${ }^{2}$, Maëlys Touya ${ }^{3 *}$ D, Lambros Chrones ${ }^{2}$, Michael Polson ${ }^{1}$ and Themmi Evangelatos ${ }^{2}$

\begin{abstract}
Background: The estimated prevalence of comorbid major depressive disorder (. MDD) is $11 \%$ in patients with type 2 diabetes (T2D) and 15-20\% in those with cardiovascular disease (CVD). Comorbid MDD continues to be a significant source of economic burden to the healthcare system.

Methods: We assessed the incremental healthcare burden of comorbid MDD in patients with T2D or CVD. This real-world, retrospective, administrative claims study analyzed commercially insured adults with T2D or CVD diagnosed on at least 2 separate claims within 12 months of each other (between January 1, 2011, and September 30, 2018). CVD included congestive heart failure, peripheral vascular disease, coronary heart disease, and cerebrovascular disease. The study compared patients with and without MDD with either T2D or CVD. Study assessments included all-cause healthcare resource utilization (proportion of patients with hospitalization, emergency department [ED] visits, and outpatient visits) and cost.

Results: Patients were matched by propensity score for demographics and baseline characteristics, resulting in similar baseline characteristics for the respective subcohorts. After matching, 22,892 patients with T2D (11,446 each with and without MDD) and 28,298 patients with CVD (14,149 each with and without MDD) were included. At follow-up, patients with T2D and MDD had significantly higher rates of hospitalization $(26.1 \%$ vs $17.4 \%, P<$ $0.0001)$ and ED visits $(55.3 \%$ vs $43.0 \%, P<0.0001)$ than those observed in patients without MDD. The total cost for patients with T2D and MDD at follow-up was significantly higher than for those without MDD (\$16,511 vs $\$ 11,550$, $P<0.0001)$. Similarly, at follow-up, patients with CVD and MDD had significantly higher rates of hospitalization (45.4\% vs $34.1 \%, P<0.0001)$ and ED visits (66.5\% vs $55.4 \%, P<0.0001)$ than those observed in patients without MDD. Total cost at follow-up for patients with CVD and MDD was significantly higher than for those without MDD $(\$ 25,546$ vs $\$ 18,041, P<0.0001)$.
\end{abstract}

Conclusions: Patients with either T2D or CVD and comorbid MDD have higher total all-cause healthcare utilization and cost than similar patients without MDD. Study findings reinforce the need for appropriate management of MDD in patients with these comorbid diseases, which in turn may result in cost reductions for payers.

\footnotetext{
* Correspondence: mtou@lundbeck.com

${ }^{3}$ Lundbeck LLC, 6 Parkway North, Deerfield, IL 60015, USA

Full list of author information is available at the end of the article
}

(c) The Author(s). 2021 Open Access This article is licensed under a Creative Commons Attribution 4.0 International License, which permits use, sharing, adaptation, distribution and reproduction in any medium or format, as long as you give appropriate credit to the original author(s) and the source, provide a link to the Creative Commons licence, and indicate if changes were made. The images or other third party material in this article are included in the article's Creative Commons licence, unless indicated otherwise in a credit line to the material. If material is not included in the article's Creative Commons licence and your intended use is not permitted by statutory regulation or exceeds the permitted use, you will need to obtain permission directly from the copyright holder. To view a copy of this licence, visit http://creativecommons.org/licenses/by/4.0/ The Creative Commons Public Domain Dedication waiver (http://creativecommons.org/publicdomain/zero/1.0/) applies to the data made available in this article, unless otherwise stated in a credit line to the data. 
Trial registration: Not applicable.

Keywords: Depression, Comorbidities, Health economics, Healthcare utilization, Pharmacoeconomics

\section{Background}

Major depressive disorder (MDD) is a common condition that is estimated to affect more than 17 million adults in the United States (US) [1]. Individuals with chronic medical conditions have an even higher prevalence of MDD than the average population [2]. This trend is also observed in patients with cardiovascular disease (CVD) who have been shown to have an MDD prevalence of 2 to 3 times higher than that of the general population [3]. Possible mechanisms that may provide a plausible link between CVD and MDD include inflammation, endothelial dysfunction, increased platelet activity and aggregation, neurohormonal and autonomic nervous system dysfunction, effects of brain-derived neurotrophic factor and related factors, and behavioral factors [4].

Similarly, MDD is a major public health issue among patients with type 2 diabetes (T2D). The prevalence of comorbid T2D is greater in patients with MDD than in the general population [5]. There is also increasing evidence that depression and diabetes may have common pathways, such as cytokine-mediated inflammatory responses and dysregulation of the hypothalamic-pituitaryadrenal (HPA) axis [6].

On the basis of the National Health and Nutrition Examination Survey data from 2013 to 2016, an estimated $10 \%$ of adults in the US (26 million) have a diagnosis of diabetes and $48 \%$ of adults aged $\geq 20$ years ( 121.5 million in 2016) have CVD [7]. The estimated prevalence of comorbid MDD is $11 \%$ in patients with diabetes and 15 to $20 \%$ in patients with CVD $[4,8,9]$. In addition, 31 to $45 \%$ of patients with coronary artery disease, unstable angina, or myocardial infarction suffer from clinically significant depressive symptoms [4].

Comorbid MDD continues to be a significant source of economic burden to the healthcare system, with costs for adults estimated at $\$ 210.5$ billion in 2010 [10]. In the limited studies that have been conducted, patients with T2D or CVD who also have depression have been shown to have higher total costs than costs for similar patients without depression. In fact, total costs for patients with diabetes and depression are 2 to $4 \frac{1}{2}$ times the costs for patients without depression, and these costs increase as depressive symptoms become more severe [11]. Similarly, among women with suspected myocardial infarction, patients with depression have been associated with a 15 to $53 \%$ increase in 5-year cardiovascular-related costs compared with those without depression [12].
As further evidence of increased utilization and costs, specifically for patients with comorbid MDD, a review of the literature revealed a prior published study that assessed use of healthcare resources among individuals with T2D with and without comorbid MDD [13]. This study found that between 2005 and 2006, patients with T2D and comorbid MDD utilized significantly more healthcare services, such as hospitalizations, emergency department $(\mathrm{ED})$ visits, and outpatient visits $(P<0.0001)$ than the services used by patients with T2D without comorbid MDD. Moreover, mean total costs per year were $\$ 8470$ higher for patients with comorbid MDD than for those without comorbid MDD ( $\$ 19,707$ vs $\$ 11,237, P<$ 0.0001) [13].

The substantial burden of comorbid MDD among patients with T2D or CVD is of significant concern, and additional data are necessary to assess its impact in realworld populations. Therefore, the objective of this hypothesis-testing study was to assess the incremental healthcare burden of MDD in patients with T2D or CVD in the US.

\section{Methods}

\section{Study design}

This was a real-world, retrospective cohort study that analyzed patients enrolled in commercial health plans using administrative medical and pharmacy claims data. The study period was defined as claims that were incurred between January 1, 2011, and September 30, 2018. The study utilized data from the medical/pharmacy database of Magellan Rx Management, which consists of claims data submitted by health plans with contracts to receive various services from Magellan (Additional file 1: Fig. S1). This database represents populations in regional health plans and contains adjudicated paid claims. The data that were analyzed represent submissions by the providers and are validated within tolerance limits. These data included information commonly required in institutional, professional, and pharmacy claims, such as dates of service, provider information, procedure codes, drug prescriptions, and financial information. A quality check was performed by the authors involved in analysis of the data for each individual health plan, prior to their inclusion in the study. In addition, consistency among monthly claim counts, patient counts, and allowed and paid amount totals were verified.

This study is exempt from Institutional Review Board requirements because it includes analyses of 
administrative claims datasets and fulfills the following exemption requirements: (1) the study does not include any individually identifiable health information, (2) the authors are authorized by the medical/pharmacy database manager of Magellan Rx Management to use the Protected Health Information (PHI) in conducting analyses performed under the "Treatment, Payment, Health Care Operations" provision of the Health Insurance Portability and Accountability Act of 1996 (HIPAA), and (3) the authors are bound by Magellan's confidentiality standards that protect individually identifiable health information, including HIPAA-compliant procedures for storage, transmission, release, and disposal of PHI.

\section{Study population}

For inclusion in the study, patients were required to have a diagnosis of T2D or CVD on at least 2 separate claims within 12 months of each other; CVD included congestive heart failure, peripheral vascular disease, coronary heart disease, and cerebrovascular disease.

Patients were also required to be $\geq 18$ years of age on the index date, which was defined as the first medical claim with a T2D or CVD diagnosis code during the identification period. Continuous enrollment in both medical and pharmacy benefits for at least 12 months before the index date through 12 or more months after the index date was also a requirement. Patients were excluded from the study if they had a diagnosis for schizophrenia or bipolar disorder at any time before the end of their healthcare plan enrollment or end of data availability, or if they became pregnant at any time during the study period.

Those patients who met the inclusion criteria were divided into 4 subcohorts, which were defined as follows: (1) patients with T2D and comorbid MDD; (2) patients with T2D without comorbid MDD; (3) patients with CVD and comorbid MDD; and (4) patients with CVD without comorbid MDD. For the 2 MDD subcohorts, patients must have had at least 2 separate diagnoses of MDD (based on the International Classification of Diseases, Ninth or Tenth Revision, Clinical Modification [ICD-9/10-CM]), with 1 of the 2 diagnoses occurring in the period between 1 year before and 1 year after the index date. Patients were included in the MDD cohort if their claims included the ICD-9-CM codes 296.2x, $296.3 \mathrm{x}, 300.4$, or 311 , or the $I C D-10-C M$ codes F32.xx, F33.xx, and F34.1.

\section{Endpoints and statistical analyses}

Patients with comorbid MDD were matched to patients without comorbid MDD by using propensity scores; the propensity scores model used matching variables that included age group, sex, region, plan type, and select comorbidities. The comorbidities were chosen based on a literature review and clinical advice, and included the following: substance/alcohol abuse disorder; T2D; hyperlipidemia; obesity; hypertension; chronic kidney disease; chronic heart disease; congestive heart failure; cerebrovascular disease; peripheral vascular disease; cancer; anxiety disorders; sleeping disorders; chronic obstructive pulmonary disease; Parkinson's disease; multiple sclerosis; and gastrointestinal disorders.

This study assessed healthcare resource utilization and costs among patients with comorbid MDD compared with the matched patients without comorbid MDD. Statistical differences between groups in healthcare resource utilization and costs were determined using $t$ tests. The following endpoints were analyzed: (1) annual all-cause healthcare resource utilization and costs during the baseline period (defined as the 12-month period prior to the index date) and (2) annual all-cause healthcare resource utilization and costs during follow-up (the period of 12 or more months after the index date), stratified by service type (including the proportions of patients requiring hospitalization; emergency department ED, laboratory, or outpatient visits; and medical and pharmacy costs). All costs were adjusted to 2018 dollars using the change in the medical care component of the Consumer Price Index [14].

All analyses were performed using SAS software version 9.4 (SAS Institute, Cary, NC).

\section{Results}

\section{Patient disposition and demographics}

Medical and pharmacy claims data were available during the study period from a total of 12.8 million patients. Of these, $969,944(7.6 \%)$ had a diagnosis of T2D on at least 2 separate claims within 12 months of each other, and $890,819(7.0 \%)$ had a diagnosis of CVD on at least 2 separate claims within 12 months of each other. Applying the remaining eligibility criteria (age, continuous enrollment, and exclusion criteria) reduced the population to 146,282 patients with T2D (11,753 with comorbid MDD and 134,529 without comorbid MDD) and 136,632 patients with CVD (14,750 with comorbid MDD and 121,882 without comorbid MDD) (Additional file 2: Table S1). Prior to matching, significant differences in demographic characteristics were evident between patients with and without comorbid MDD for both the T2D and CVD populations.

Following matching, the respective subcohorts with and without comorbid MDD had similar demographics (Table 1). Matching the patients with comorbid MDD to patients without comorbid MDD using propensity scores resulted in a final study population of 22,892 patients with T2D (11,446 with comorbid MDD and 11,446 without comorbid MDD) and 28,298 patients with CVD 
Table 1 Patient demographics after matching

\begin{tabular}{|c|c|c|c|c|c|c|c|c|}
\hline \multirow[t]{2}{*}{ Characteristic } & \multicolumn{4}{|c|}{ Patients with T2D } & \multicolumn{4}{|c|}{ Patients with CVD } \\
\hline & $\begin{array}{l}\text { All } \\
\text { patients } \\
(n= \\
22,892)\end{array}$ & $\begin{array}{l}\text { With comorbid } \\
\text { MDD } \\
(n=11,446)\end{array}$ & $\begin{array}{l}\text { Without comorbid } \\
\text { MDD } \\
(n=11,446)\end{array}$ & $\begin{array}{l}P \\
\text { value }\end{array}$ & $\begin{array}{l}\text { All patients } \\
(n=28,298)\end{array}$ & $\begin{array}{l}\text { With comorbid } \\
\text { MDD } \\
(n=14,149)\end{array}$ & $\begin{array}{l}\text { Without comorbid } \\
\text { MDD } \\
(n=14,149)\end{array}$ & $\begin{array}{l}P \\
\text { value }\end{array}$ \\
\hline \multicolumn{9}{|l|}{ Age, years } \\
\hline Mean (SD) & $52.8(9.8)$ & $51.3(9.4)$ & $51.2(9.5)$ & 0.08 & $52.8(9.3)$ & $52.8(9.4)$ & $52.9(9.3)$ & 0.59 \\
\hline \multicolumn{9}{|c|}{ Age group, years, n (\%) } \\
\hline $18-29$ & $580(2.5)$ & $301(2.6)$ & $279(2.4)$ & 0.45 & $667(2.4)$ & $345(2.4)$ & $322(2.3)$ & 0.83 \\
\hline $30-39$ & $1820(8.0)$ & $939(8.2)$ & $881(7.7)$ & & $1630(5.8)$ & $810(5.7)$ & $820(5.8)$ & \\
\hline $40-49$ & $6030(26.3)$ & $3004(26.2)$ & $3026(26.4)$ & & $5872(20.8)$ & $2928(20.7)$ & $2944(20.8)$ & \\
\hline $50-59$ & $\begin{array}{l}10,015 \\
(43.7)\end{array}$ & $4970(43.4)$ & $5045(44.1)$ & & $13,303(47.0)$ & $6627(46.8)$ & $6676(47.2)$ & \\
\hline $60-69$ & $4266(18.6)$ & 2133 (18.6) & $2133(18.6)$ & & $6408(22.6)$ & $3217(22.7)$ & 3191 (22.6) & \\
\hline 70-79 & $174(0.8)$ & $94(0.8)$ & $80(0.7)$ & & $375(1.3)$ & $199(1.4)$ & $176(1.2)$ & \\
\hline$\geq 80$ & $7(0.0)$ & $5(0.0)$ & $2(0.0)$ & & $43(0.2)$ & $23(0.2)$ & $20(0.1)$ & \\
\hline \multicolumn{9}{|l|}{ Sex, n (\%) } \\
\hline Female & $\begin{array}{l}13,947 \\
(60.9)\end{array}$ & 6969 (60.9) & $6978(61.0)$ & 0.91 & $16,809(59.4)$ & $8379(59.2)$ & 8430 (59.6) & 0.55 \\
\hline Male & 8945 (39.1) & 4477 (39.1) & $4468(39.0)$ & & $11,489(40.6)$ & $5770(40.8)$ & $5719(40.4)$ & \\
\hline \multicolumn{9}{|c|}{ Plan type, n (\%) } \\
\hline PPO/POS & $\begin{array}{l}19,337 \\
(84.5)\end{array}$ & 9621 (84.1) & 9716 (84.9) & 0.19 & 23,528 (83.1) & $11,724(82.9)$ & 11,804 (83.4) & 0.44 \\
\hline $\mathrm{HMO}$ & $1626(7.1)$ & $843(7.4)$ & 783 (6.8) & & 2504 (8.8) & $1271(9.0)$ & $1233(8.7)$ & \\
\hline Other & $1929(8.4)$ & 982 (8.6) & 947 (8.3) & & 2266 (8.0) & $1154(8.2)$ & $1112(7.9)$ & \\
\hline
\end{tabular}

Statistical differences were assessed using $t$ tests

CVD cardiovascular disease, HMO health maintenance organization, $M D D$ major depressive disorder, $P O S$ point of service, $P P O$ preferred provider organization, $S D$ standard deviation, $T 2 D$ type 2 diabetes

Table 2 Healthcare resource utilization and annual costs during the baseline period

\begin{tabular}{|c|c|c|c|c|c|c|}
\hline & \multicolumn{3}{|l|}{ Patients with T2D } & \multicolumn{3}{|l|}{ Patients with CVD } \\
\hline & $\begin{array}{l}\text { With comorbid MDD } \\
(n=11,446)\end{array}$ & $\begin{array}{l}\text { Without comorbid MDD } \\
(n=11,446)\end{array}$ & $P$ value & $\begin{array}{l}\text { With comorbid MDD } \\
(n=14,149)\end{array}$ & $\begin{array}{l}\text { Without comorbid MDD } \\
(n=14,149)\end{array}$ & $P$ value \\
\hline \multicolumn{7}{|c|}{ Baseline average duration of analysis, months } \\
\hline Mean (SD) & $43.1(28.9)$ & $43.1(28.0)$ & 0.99 & $42.8(29.8)$ & $43.4(29.6)$ & 0.11 \\
\hline \multicolumn{7}{|c|}{ All-cause healthcare resource utilization during the baseline period, $n(\%)$} \\
\hline \multicolumn{7}{|c|}{ Proportion of patients requiring: } \\
\hline Hospitalizations & $1222(10.7)$ & $872(7.6)$ & $<0.0001$ & $2250(15.9)$ & $1606(11.4)$ & $<0.0001$ \\
\hline ED visits & $4368(38.2)$ & $3890(34.0)$ & $<0.0001$ & $7121(50.3)$ & $6431(45.5)$ & $<0.0001$ \\
\hline Outpatient visits & $10,777(94.2)$ & $10,606(92.7)$ & $<0.0001$ & $13,887(98.1)$ & $13,786(97.4)$ & $<0.0001$ \\
\hline \multicolumn{7}{|c|}{ Annual all-cause costs during the baseline period, $\$$} \\
\hline \multicolumn{7}{|l|}{ Pharmacy } \\
\hline Mean (SD) & $1859(6203)$ & $1206(4265)$ & $<0.0001$ & $2498(6931)$ & 1775 (7679) & $<0.0001$ \\
\hline \multicolumn{7}{|l|}{ Medical } \\
\hline Mean (SD) & $6127(20,069)$ & $4484(15,874)$ & $<0.0001$ & $8112(22,857)$ & $6335(23,142)$ & $<0.0001$ \\
\hline \multicolumn{7}{|l|}{ Total } \\
\hline Mean (SD) & $7986(22,158)$ & $5689(17,467)$ & $<0.0001$ & $10,610(25,425)$ & $8110(25,077)$ & $<0.0001$ \\
\hline
\end{tabular}

Statistical differences were assessed using $t$ tests. Significant $P$ values $(<0.05)$ are shown in bold italic.

CVD cardiovascular disease, ED emergency department, MDD major depressive disorder, SD standard deviation, T2D type 2 diabetes 
(14,149 with comorbid MDD and 14,149 without comorbid MDD).

\section{Healthcare resource utilization and costs during the baseline period}

The results presented here are for matched patients. During the baseline period, significantly more patients with T2D or CVD and comorbid MDD required hospitalization, ED visits, or outpatient visits than did patients without comorbid MDD (all $P<0.0001$; Table 2).

During the baseline period, mean annual total costs (inclusive of pharmacy and medical costs) were all significantly greater for patients with T2D or CVD and comorbid MDD than for matched patients without comorbid MDD (all $P<0.0001$; Table 2).
Healthcare resource utilization and costs during follow-up During the follow-up period, significantly more patients with T2D and comorbid MDD required hospitalization, ED visits, or outpatient visits than did patients without comorbid MDD (all $P \leq 0.0025$; Table 3). Similarly, significantly more patients with CVD and comorbid MDD required hospitalization or ED visits than did patients without comorbid MDD (both $P<0.0001$; Table 3). The mean numbers of hospitalizations and ED, laboratory, and outpatient visits, the mean number of prescriptions per patient, and the mean length of stay during followup were also significantly higher in patients with T2D or CVD and comorbid MDD than in patients without comorbid MDD (all $P<0.0001$; Table 3).

During follow-up, mean annual all-cause costs stratified by service type were all significantly greater for patients with T2D or CVD and comorbid MDD than for

Table 3 All-Cause healthcare resource utilization during the follow-up period

\begin{tabular}{|c|c|c|c|c|c|c|}
\hline & \multicolumn{3}{|l|}{ Patients with T2D } & \multicolumn{3}{|l|}{ Patients with CVD } \\
\hline & $\begin{array}{l}\text { With comorbid MDD } \\
(n=11,446)\end{array}$ & $\begin{array}{l}\text { Without comorbid MDD } \\
(n=11,446)\end{array}$ & $P$ value & $\begin{array}{l}\text { With comorbid MDD } \\
(n=14,149)\end{array}$ & $\begin{array}{l}\text { Without comorbid MDD } \\
(n=14,149)\end{array}$ & $P$ value \\
\hline \multicolumn{7}{|c|}{ Average follow-up time, months } \\
\hline Mean (SD) & $33.1(16.7)$ & $32.0(16.2)$ & $<0.0001$ & $29.7(14.0)$ & $29.2(13.8)$ & 0.0016 \\
\hline \multicolumn{7}{|c|}{ Proportion of patients requiring, $n(\%)$ : } \\
\hline Hospitalizations & $2989(26.1)$ & $1986(17.4)$ & $<0.0001$ & $6419(45.4)$ & $4826(34.1)$ & $<0.0001$ \\
\hline ED visits & $6328(55.3)$ & $4918(43.0)$ & $<0.0001$ & $9411(66.5)$ & $7832(55.4)$ & $<0.0001$ \\
\hline Outpatient visits & $11,443(100.0)$ & $11,429(99.9)$ & 0.0025 & $14,146(100.0)$ & $14,144(100.0)$ & 0.73 \\
\hline \multicolumn{7}{|c|}{ Hospitalizations per patient } \\
\hline Mean (SD) & $0.3(0.8)$ & $0.1(0.4)$ & $<0.0001$ & $0.5(1.2)$ & $0.3(0.8)$ & $<0.0001$ \\
\hline \multicolumn{7}{|c|}{ Length of stay, days } \\
\hline Mean (SD) & $1.6(7.6)$ & $0.7(3.3)$ & $<0.0001$ & $3.6(11.3)$ & $1.8(6.4)$ & $<0.0001$ \\
\hline \multicolumn{7}{|c|}{ ED visits per patient } \\
\hline Mean (SD) & $0.9(2.5)$ & $0.6(1.9)$ & $<0.0001$ & $1.3(2.8)$ & $0.9(2.8)$ & $<0.0001$ \\
\hline \multicolumn{7}{|c|}{ Laboratory visits per patient } \\
\hline Mean (SD) & $3.9(5.0)$ & $3.2(3.8)$ & $<0.0001$ & $4.5(5.6)$ & $3.7(4.9)$ & $<0.0001$ \\
\hline \multicolumn{7}{|c|}{ Outpatient visits per patient } \\
\hline Mean (SD) & $21.4(18.6)$ & $14.4(13.8)$ & $<0.0001$ & $26.5(21.3)$ & $18.5(16.5)$ & $<0.0001$ \\
\hline \multicolumn{7}{|l|}{ Primary care visits } \\
\hline Mean (SD) & $4.9(4.2)$ & $4.1(4.0)$ & $<0.0001$ & $5.0(4.6)$ & $4.0(4.1)$ & $<0.0001$ \\
\hline \multicolumn{7}{|l|}{ Psychiatrist visits } \\
\hline Mean (SD) & $1.1(3.1)$ & $0.1(1.1)$ & $<0.0001$ & $1.2(3.5)$ & $0.1(0.9)$ & $<0.0001$ \\
\hline \multicolumn{7}{|c|}{ Behavioral therapy visits } \\
\hline Mean (SD) & $3.3(8.9)$ & $0.5(3.0)$ & $<0.0001$ & $3.6(8.8)$ & $0.6(3.8)$ & $<0.0001$ \\
\hline \multicolumn{7}{|c|}{ Prescriptions per patient } \\
\hline Mean (SD) & $6.1(7.8)$ & $4.4(6.0)$ & $<0.0001$ & $7.4(8.6)$ & $5.2(6.5)$ & $<0.0001$ \\
\hline
\end{tabular}

Statistical differences were assessed using $t$ tests. Significant $P$ values $(<0.05)$ are shown in bold italic.

$C V D$ cardiovascular disease, $E D$ emergency department, $M D D$ major depressive disorder, $S D$ standard deviation, $T 2 D$ type 2 diabetes 
patients without comorbid MDD $(P<0.0001$ for all but "Other Costs" where $P=0.0015$; Table 4$)$. The mean total annual all-cause cost (pharmacy and medical) was greater by $\$ 4961$ in patients with T2D and comorbid MDD than in matched patients without comorbid MDD ( $\$ 16,511$ vs $\$ 11,550, P<0.0001$; Table 4 and Fig. 1$)$. Similarly, the mean total annual all-cause cost (pharmacy and medical) was greater by $\$ 7505$ in patients with CVD and comorbid MDD than in matched patients without comorbid MDD ( $\$ 25,546$ vs $\$ 18,041, P<0.0001$; Table 4 and Fig. 1).

\section{Discussion}

In this study, patients with either T2D or CVD and comorbid MDD had higher total all-cause healthcare utilization and costs than those reported for similar patients without comorbid MDD. Significantly more patients with T2D or CVD and comorbid MDD required hospitalization and ED visits than did matched patients without comorbid MDD. Mean annual all-cause costs stratified by service type were all significantly greater for patients with T2D or CVD and comorbid MDD than for matched patients without comorbid MDD.

Evidence from previous studies has similarly demonstrated higher healthcare utilization and costs among patients with either T2D or CVD and comorbid depression than in those without depression. As noted, earlier studies found that costs for patients with diabetes and depression were about twice those for patients without depression [11, 13]; in women with suspected myocardial infarction, cardiovascular-related costs were higher for patients with depression than for those without depression [12]. Our findings are consistent with the existing literature and add data from a large population of patients with T2D or CVD and comorbid MDD, further adding to the published base of evidence.

One possible explanation for our findings is that patients with poorly managed MDD are less able to effectively manage their comorbid chronic conditions. Consistent with this speculation, comorbid MDD and diabetes have been associated with suboptimal glycemic control and an increase in diabetes-related complications, which may be due to the fact that MDD can

Table 4 Annual all-cause costs during the follow-up period

\begin{tabular}{|c|c|c|c|c|c|c|c|c|}
\hline \multirow{2}{*}{$\begin{array}{l}\text { Annual } \\
\text { all-cause } \\
\text { cost, \$ }\end{array}$} & \multicolumn{4}{|c|}{ Patients with T2D } & \multicolumn{4}{|c|}{ Patients with CVD } \\
\hline & $\begin{array}{l}\text { All patients } \\
(n=22,892)\end{array}$ & $\begin{array}{l}\text { With comorbid } \\
\text { MDD } \\
(n=11,446)\end{array}$ & $\begin{array}{l}\text { Without comorbid } \\
\text { MDD } \\
(n=11,446)\end{array}$ & $\begin{array}{l}P \\
\text { value }\end{array}$ & $\begin{array}{l}\text { All patients } \\
(n=28,298)\end{array}$ & $\begin{array}{l}\text { With comorbid } \\
\text { MDD } \\
(n=14,149)\end{array}$ & $\begin{array}{l}\text { Without comorbid } \\
\text { MDD } \\
(n=14,149)\end{array}$ & $\begin{array}{l}P \\
\text { value }\end{array}$ \\
\hline \multicolumn{9}{|c|}{ Hospitalization costs } \\
\hline $\begin{array}{l}\text { Mean } \\
\text { (SD) }\end{array}$ & $1120(7851)$ & $1453(9849)$ & $788(5105)$ & $\begin{array}{l}< \\
0.0001\end{array}$ & $\begin{array}{l}2322 \\
(10,245)\end{array}$ & $2865(12,120)$ & $1778(7903)$ & $\begin{array}{l}< \\
0.0001\end{array}$ \\
\hline \multicolumn{9}{|l|}{ ED costs } \\
\hline $\begin{array}{l}\text { Mean } \\
\text { (SD) }\end{array}$ & $878(3387)$ & $1087(4321)$ & 669 (2047) & $\begin{array}{l}< \\
0.0001\end{array}$ & $1440(3711)$ & $1746(4508)$ & $1134(2652)$ & $\begin{array}{l}< \\
0.0001\end{array}$ \\
\hline \multicolumn{9}{|c|}{ Laboratory costs } \\
\hline $\begin{array}{l}\text { Mean } \\
\text { (SD) }\end{array}$ & 700 (2208) & $799(2721)$ & $601(1527)$ & $\begin{array}{l}< \\
0.0001\end{array}$ & $818(2279)$ & $930(2723)$ & 705 (1716) & $\begin{array}{l}< \\
0.0001\end{array}$ \\
\hline \multicolumn{9}{|c|}{ Outpatient costs } \\
\hline $\begin{array}{l}\text { Mean } \\
\text { (SD) }\end{array}$ & $\begin{array}{l}7116 \\
(21,936)\end{array}$ & $8283(20,686)$ & $5950(23,061)$ & $\begin{array}{l}< \\
0.0001\end{array}$ & $\begin{array}{l}11,005 \\
(26,441)\end{array}$ & $12,658(28,902)$ & $9351(23,611)$ & $\begin{array}{l}< \\
0.0001\end{array}$ \\
\hline \multicolumn{9}{|c|}{ Other costs } \\
\hline $\begin{array}{l}\text { Mean } \\
\text { (SD) }\end{array}$ & $\begin{array}{l}1906 \\
(14,082)\end{array}$ & $2202(14,950)$ & $1610(13,150)$ & 0.0015 & $\begin{array}{l}3383 \\
(16,220)\end{array}$ & $3989(18,373)$ & $2778(13,707)$ & $\begin{array}{l}< \\
0.0001\end{array}$ \\
\hline \multicolumn{9}{|c|}{ Medical costs } \\
\hline $\begin{array}{l}\text { Mean } \\
\text { (SD) }\end{array}$ & $\begin{array}{l}11,720 \\
(31,188)\end{array}$ & $13,823(32,023)$ & $9618(30,186)$ & $\begin{array}{l}< \\
0.0001\end{array}$ & $\begin{array}{l}18,968 \\
(38,326)\end{array}$ & $22,189(42,317)$ & $15,746(33,561)$ & $\begin{array}{l}< \\
0.0001\end{array}$ \\
\hline \multicolumn{9}{|c|}{ Pharmacy costs } \\
\hline $\begin{array}{l}\text { Mean } \\
\text { (SD) }\end{array}$ & $2310(7602)$ & $2688(8606)$ & $1932(6423)$ & $\begin{array}{l}< \\
0.0001\end{array}$ & $2826(8409)$ & $3358(9233)$ & $2295(7458)$ & $\begin{array}{l}< \\
0.0001\end{array}$ \\
\hline \multicolumn{9}{|c|}{ Total costs (pharmacy and medical) } \\
\hline $\begin{array}{l}\text { Mean } \\
\text { (SD) }\end{array}$ & $\begin{array}{l}14,031 \\
(33,286)\end{array}$ & $16,511(34,415)$ & $11,550(31,928)$ & $\begin{array}{l}< \\
0.0001\end{array}$ & $\begin{array}{l}21,794 \\
(40,557)\end{array}$ & $25,546(44,796)$ & $18,041(35,425)$ & $\begin{array}{l}< \\
0.0001\end{array}$ \\
\hline
\end{tabular}

Statistical differences were assessed using $t$ tests. Significant $P$ values $(<0.05)$ are shown in bold italic.

CVD cardiovascular disease, ED emergency department, MDD major depressive disorder, SD standard deviation, $T 2 D$ type 2 diabetes 


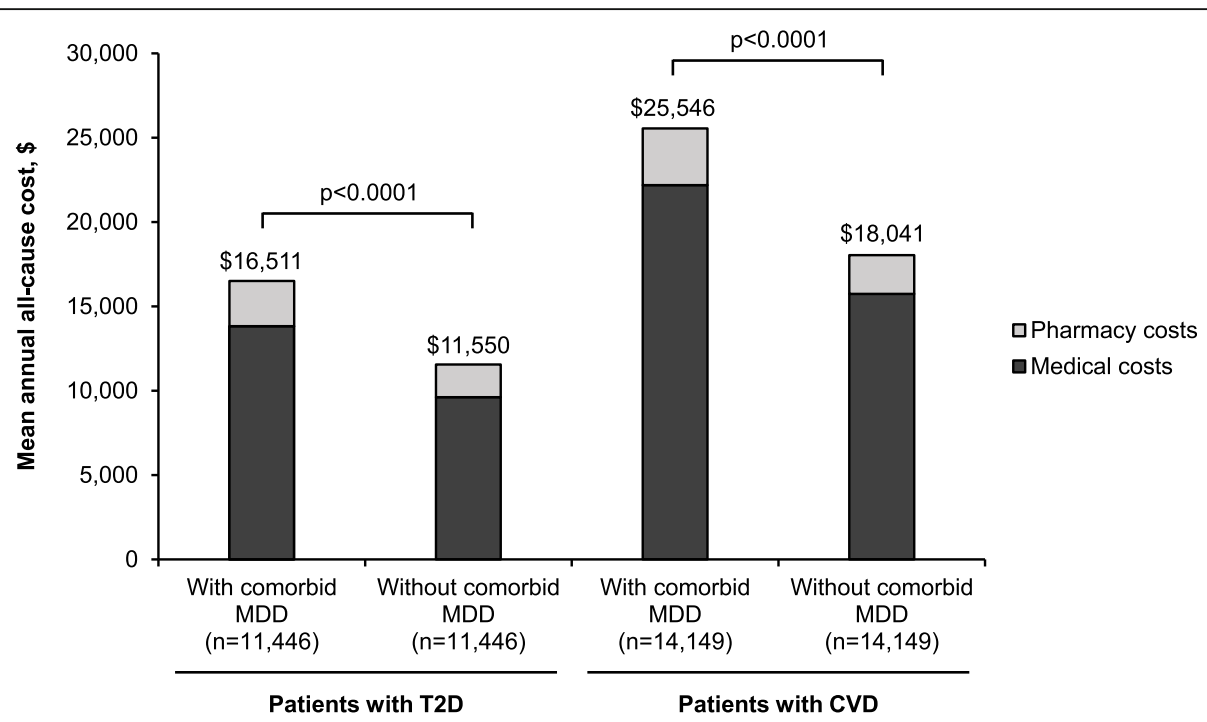

Fig. 1 Total annual all-cause cost in patients with T2D or CVD with/without comorbid MDD during follow-up. Statistical differences were assessed using $t$ tests. CVD cardiovascular disease, MDD major depressive disorder, T2D type 2 diabetes

impair a patient's self-management of T2D [15]. If this is true, more effective treatment of depressive symptoms may enable patients to better manage their chronic diseases. Consistent with this idea, a recently published study found that among 1568 patients with comorbid MDD and CVD (prior myocardial infarction or stroke), those who received adequate treatment for MDD had significantly fewer all-cause hospitalizations, outpatient visits, CVD-related ED visits, and CVD-related outpatient visits than those who received insufficient treatment for their MDD [16]. In this same study, patients with adequate MDD treatment also incurred significantly lower mean all-cause outpatient costs (\$2055 vs $\$ 2820$ per-patient per-year; $P<0.001), \quad C V D-$ related hospitalization costs $(\$ 17,756$ vs $\$ 21,485$ per-patient per-year; $P=0.04$ ), and CVD-related outpatient costs ( $\$ 434$ vs $\$ 520$ per-patient per-year; $P=0.03$ ) [16].

Thus, clinicians should be especially conscious of the importance of effective management of MDD in patients who also have comorbid physical disorders, both to improve patients' mental health as well as their ability to manage their comorbid conditions. Key to effective management of any chronic condition is patients' adherence to prescribed therapy. Comorbid MDD has been previously shown to have a negative impact on treatment adherence for patients with CVD or T2D, which has been associated with poorer outcomes in some studies [15, 17]. Medication nonadherence in patients with comorbid MDD and CVD occurs at a rate more than double that of patients without MDD [17].

Adherence to antidepressant therapy in turn supports adherence to therapy for comorbid physical conditions and better physical health outcomes. For example, among patients with comorbid T2D and MDD, those with better adherence and persistence to antidepressants have demonstrated improved adherence to oral antidiabetic medications, better glycemic control, and lower total all-cause and medical costs [15]. In addition to the impact of adherence to antidepressant therapy in assisting patients to better manage comorbid health conditions, depression and both T2D and CVD also share certain common physiological pathways $[4,6]$. Thus, effective management of MDD may also have direct benefits on the physical health disorder. In summary, effective management of MDD has the potential to improve physical health outcomes and reduce healthcare utilization and costs among patients with comorbid diseases.

\section{Limitations}

Several limitations in our study should be considered: (1) Real-world claims data can be subject to outliers, which can skew data on healthcare costs and lead to mean values that are higher than expected; (2) Services that are performed but not billed are not captured in this study; (3) Our data depend on professional ICD-9/ 10 coding and the different coding patterns that are used in the clinical setting may not all be accurate - this is also true for other claims-based analyses [18]; and (4) Since this study did not assess treatment for MDD, the subcohorts likely contained a mix of appropriately treated and suboptimally treated/non-treated patients.

In addition, the results of this analysis may not be generalizable to non-commercial plans with potentially different populations and policies, such as Medicaid. Socioeconomic data that would support additional analyses 
are not available in the claims. Lastly, studies with large sample sizes may reveal small differences between groups that are determined to be statistically significant, but may not be clinically meaningful. As a result, small statistically significant differences that are observed in large studies should be evaluated for their clinical relevance.

\section{Conclusions}

Patients with either T2D or CVD and comorbid MDD have higher total all-cause healthcare utilization and costs compared with similar patients without comorbid MDD. These findings reinforce the need for appropriate management of MDD in patients with T2D or CVD, which in turn may result in a decrease in healthcare utilization, as well as cost reductions for patients, payers, and the entire healthcare system. Further studies are warranted to elucidate whether higher healthcare resource utilization and costs in these patients are due to managing comorbid MDD itself or to managing more severe or less well-controlled T2D or CVD associated with comorbid MDD.

\section{Abbreviations}

CVD: Cardiovascular disease; ED: Emergency department; HIPAA: Health Insurance Portability and Accountability Act; HMO: Health maintenance organization; HPA: Hypothalamic-pituitary-adrenal; ICD-9/10-CM: International Classification of Diseases, Ninth or Tenth Revision, Clinical Modification; MDD: Major depressive disorder; PHI: Protected Health Information; POS: Point of service; PPO: Preferred provider organization; SD: Standard deviation; T2D: Type 2 diabetes; US: United States

\section{Supplementary Information}

The online version contains supplementary material available at https://doi. org/10.1186/s12913-021-06802-9.

Additional file 1 Table S1. Patient attrition. Fig. S1. Study design.

\section{Acknowledgments}

Not applicable.

\section{Authors' contributions}

AK contributed to the study concept, supervised data collection, interpreted the study results, and contributed to the writing of the manuscript (critical review and editing). MP contributed to the study concept, supervised data collection, verified and interpreted the study results, and contributed to the writing of the manuscript (critical review and editing). DFL contributed to the study concept, developed the study protocol, planned the data analysis, interpreted the study results, and contributed to the writing of the manuscript (critical review and editing). TE contributed to the study concept, coordinated project operations, interpreted the study results, and contributed to the writing of the manuscript (critical review and editing). LC contributed to the study concept, developed the study protocol, planned the data analysis, interpreted the study results, and contributed to the writing of the manuscript (critical review and editing). MT contributed to the study concept, developed the study protocol, planned the data analysis, interpreted the study results, and contributed to the writing of the manuscript (critical review and editing). All authors read and approved the final manuscript.

\section{Funding}

The study was funded by Takeda Pharmaceuticals U.S.A., Inc., and Lundbeck LLC. Medical writing assistance, provided by Syneos Health Medical Communications, LLC, was supported by Takeda Pharmaceuticals U.S.A., Inc., and Lundbeck LLC.

\section{Availability of data and materials}

The datasets generated during and/or analyzed during the current study are not publicly available since the research data contains protected patient health information and cannot be made available without violating privacy laws.

\section{Declarations}

Ethics approval and consent to participate

Not applicable (non-interventional retrospective study using existing data from Magellan's medical/pharmacy claims database).

\section{Consent for publication}

Not applicable.

\section{Competing interests}

AK and MP are employees of Magellan Method, a Division of Magellan Rx Management. DFL, TE, and LC are employees of Takeda Pharmaceuticals U.S.A., Inc. MT is an employee of Lundbeck LLC. The sponsors were responsible for study design; collection, analysis, and interpretation of data; and the decision to submit the report for publication.

\section{Author details}

${ }^{1}$ Magellan Method, a Division of Magellan Rx Management, 35 Landsdowne St, Scottsdale, AZ 85251, USA. ${ }^{2}$ Takeda Pharmaceuticals U.S.A., Inc., 95 Hayden Ave, Lexington, MA 02421, USA. ${ }^{3}$ Lundbeck LLC, 6 Parkway North, Deerfield, IL 60015, USA.

Received: 3 November 2020 Accepted: 19 July 2021

Published online: 06 August 2021

References

1. National Institute of Mental Health. Statistics: major depression 2017. https:// www.nimh.nih.gov/health/statistics/major-depression.shtml. Accessed 15 August 2019.

2. Katon WJ. Clinical and health services relationships between major depression, depressive symptoms, and general medical illness. Biol Psychiatry. 2003;54:216-26.

3. Hare DL, Toukhsati SR, Johansson P, Jaarsma T. Depression and cardiovascular disease: a clinical review. Eur Heart J. 2014:35:1365-72.

4. Huffman JC, Celano CM, Beach SR, Motiwala SR, Januzzi JL. Depression and cardiac disease: epidemiology, mechanisms, and diagnosis. Cardiovasc Psychiatry Neurol. 2013;2013:695925.

5. Vancampfort D, Correll CU, Galling B, Probst M, De Hert M, Ward PB, et al. Diabetes mellitus in people with schizophrenia, bipolar disorder and major depressive disorder: a systematic review and large scale meta-analysis. World Psychiatry. 2016;15:166-74.

6. Moulton CD, Pickup JC, Ismail K. The link between depression and diabetes: the search for shared mechanisms. Lancet Diabetes Endocrinol. 2015;3:46171.

7. Benjamin EJ, Muntner P, Alonso A, Bittencourt MS, Callaway CW, Carson AP, et al. Heart disease and stroke statistics-2019 update: a report from the American Heart Association. Circulation. 2019;139:e56-e528.

8. Anderson RJ, Freedland KE, Clouse RE, Lustman PJ. The prevalence of comorbid depression in adults with diabetes: a meta-analysis. Diabetes Care. 2001;24:1069-78.

9. Colquhoun DM, Bunker SJ, Clarke DM, Glozier N, Hare DL, Hickie IB, et al. Screening, referral and treatment for depression in patients with coronary heart disease. Med J Aust. 2013;198:483-4.

10. Greenberg PE, Fournier AA, Sisitsky T, Pike CT, Kessler RC. The economic burden of adults with major depressive disorder in the United States (2005 and 2010). J Clin Psychiatry. 2015;76:155-62.

11. Egede LE, Bishu KG, Walker RJ, Dismuke CE. Impact of diagnosed depression on healthcare costs in adults with and without diabetes: United States, 2004-2011. J Affect Disord. 2016;195:119-26. 
12. Rutledge $T$, Vaccarino V, Johnson BD, Bittner V, Olson MB, Linke SE, et al. Depression and cardiovascular health care costs among women with suspected myocardial ischemia: prospective results from the WISE (Women's ischemia syndrome evaluation) study. J Am Coll Cardiol. 2009:53:176-83.

13. Le TK, Curtis B, Kahle-Wrobleski K, Johnston J, Haldane D, Melfi C. Treatment patterns and resource use among patients with comorbid diabetes mellitus and major depressive disorder. J Med Econ. 2011;14:440-7.

14. US Bureau of Labor Statistics. Consumer Price Index. Archived Consumer Price Index Detailed Reports: Detailed Reports (ZIP); 2017. https://www.bls. gov/cpi/tables/detailed-reports/home.htm. Accessed 07 June 2021

15. Vega C, Becker RV, Mucha L, Lorenz BH, Eaddy MT, Ogbonnaya AO. Impact of adherence to antidepressants on healthcare outcomes and costs among patients with type 2 diabetes and comorbid major depressive disorder. Curr Med Res Opin. 2017;33:1879-89.

16. Bangalore S, Shah R, Gao X, Pappadopulos E, Deshpande CG, Shelbaya A, et al. Economic burden associated with inadequate antidepressant medication management among patients with depression and known cardiovascular diseases: insights from a United States-based retrospective claims database analysis. J Med Econ. 2020;23:262-70.

17. Gehi A, Haas D, Pipkin S, Whooley MA. Depression and medication adherence in outpatients with coronary heart disease: findings from the heart and soul study. Arch Intern Med. 2005;165:2508-13.

18. Tyree PT, Lind BK, Lafferty WE. Challenges of using medical insurance claims data for utilization analysis. Am J Med Qual. 2006;21:269-75.

\section{Publisher's Note}

Springer Nature remains neutral with regard to jurisdictional claims in published maps and institutional affiliations.

Ready to submit your research? Choose BMC and benefit from:

- fast, convenient online submission

- thorough peer review by experienced researchers in your field

- rapid publication on acceptance

- support for research data, including large and complex data types

- gold Open Access which fosters wider collaboration and increased citations

- maximum visibility for your research: over $100 \mathrm{M}$ website views per year

At $\mathrm{BMC}$, research is always in progress.

Learn more biomedcentral.com/submissions 